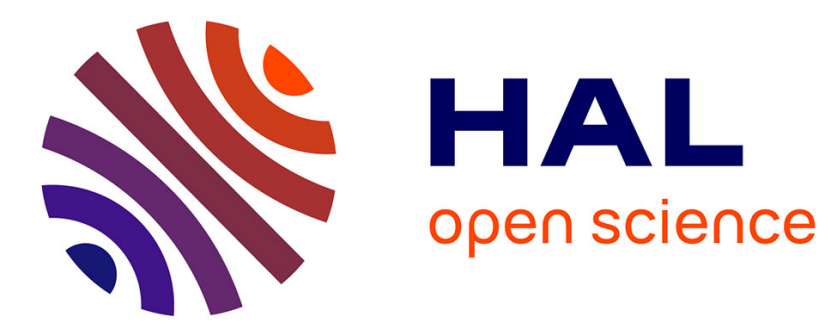

\title{
Coupling Binary and Ternary Information in Assessing the Fcc/Hcp Relative Phase Stability and Martensitic Transformation in Fe-Mn-Co and Fe-Mn-Si Alloys
}

\author{
A. Baruj, S. Cotes, M. Sade, A. Fernández Guillermet
}

\section{- To cite this version:}

A. Baruj, S. Cotes, M. Sade, A. Fernández Guillermet. Coupling Binary and Ternary Information in Assessing the Fcc/Hcp Relative Phase Stability and Martensitic Transformation in Fe-MnCo and Fe-Mn-Si Alloys. Journal de Physique IV Proceedings, 1995, 05 (C8), pp.C8-373-C8-378. 10.1051/jp4:1995855 . jpa-00254104

HAL Id: jpa-00254104

https://hal.science/jpa-00254104

Submitted on 1 Jan 1995

HAL is a multi-disciplinary open access archive for the deposit and dissemination of scientific research documents, whether they are published or not. The documents may come from teaching and research institutions in France or abroad, or from public or private research centers.
L'archive ouverte pluridisciplinaire HAL, est destinée au dépôt et à la diffusion de documents scientifiques de niveau recherche, publiés ou non, émanant des établissements d'enseignement et de recherche français ou étrangers, des laboratoires publics ou privés. 


\title{
Coupling Binary and Ternary Information in Assessing the Fcc/Hcp Relative Phase Stability and Martensitic Transformation in Fe-Mn-Co and Fe-Mn-Si Alloys
}

\author{
A. Baruj, S. Cotes, M. Sade and A. Fernández Guillermet* \\ Comisión Nacional de Energía Atómica, Centro Atómico Bariloche e Instituto Balseiro, 8400 S.C. de \\ Bariloche (RN), Argentina \\ * Consejo Nacional de Investigaciones Cientificas y Técnicas, CONICET, Argentina
}

\begin{abstract}
This paper presents a study of the composition dependence of the fcc/hcp martensitic transformation temperatures and relative phase stability of these structures in Fe-Mn-Co and Fe-Mn-Si alloys. The approach combines new experimental determinations of $\mathrm{M}_{s}$ and $\mathrm{A}_{\mathrm{s}}$ in the binary systems Fe-Mn and $\mathrm{Fe}-\mathrm{Co}$, and in both ternary systems with a critical analysis of the previously published experimental data, and thermodynamic calculations. It is shown how this combination of binary and ternary information with various methods of analysis can be used to establish the $\mathrm{T}_{0}$-temperatures in the Fe-Mn-Co system and to refine the thermodynamic description of the metastable hcp structure of the Fe-Co system. The present methods also help to detect possible inconsistencies in the previously reported $M_{s}$ and $A_{s}$ data for Fe-Mn-Si alloys, which is used as a basis for discussing the most recent calculation of $M_{s}$ temperatures in this system.
\end{abstract}

\section{INTRODUCTION}

The fcc/hcp martensitic transformation in Fe-based alloys has been the subject of a renewed interest in the last decades, in connection with the so-called shape-memory effect (SME). In particular, there has been a considerable interest in studying the behaviour of ternary and higher-order alloys based on the Fe-Mn system, a binary that has long been known to show a weak SME [1]. The relative stability of these two structures is conveniently characterised using their Gibbs energy $\left(\mathrm{G}_{\mathrm{m}}\right)$ as a function of temperature $(T)$ and composition ( $\mathrm{x}$ ). The $\mathrm{G}_{\mathrm{m}}$ function of the fcc phase $\left(\mathrm{G}_{\mathrm{m}}^{\mathrm{fcc}}\right)$, which is in general a stable phase in Fe-Mn-X systems, might be obtained by coupling thermochemical and phase diagram data, as it is usually done in the so-called CALPHAD approach to phase stability of multicomponent alloys [2]. This approach relies on mathematical models for $G_{m}$, the parameters of which are determined by combining thermodynamic information on each of the binary subsystems (i.e., the Fe-Mn, Fe-X and $\mathrm{Mn}$-X systems) with experimental phase diagram data on ternary alloys. However, the hep phase is metastable in most Fe-based alloys and thus its $G_{m}$ function might not be well known in the binary subsystems. In the present work we shall concentrate on the interplay between binary and ternary information in assessing the martensitic transformation (MT) data and the phase stability of alloys in two ternary systems, viz, the Fe-Mn-Co and the Fe-Mn-Si systems. Our approach to this problem is as follows. Previously we established the MT temperatures and Gibbs energy functions for the Fe-Mn system $[3,4]$. Here we turn to the Fe-Mn-Co system and start by performing MT experiments in ternary alloys as well as in the other relevant binary, viz., the FeCo system. Next we show how this body of binary and ternary information can be treated thermodynamically in a consistent way. Finally, we review and discuss the available MT data in the Fe-MnSi system, in the light of the new experiments reported here and the recent analysis by Forsberg and Agren [5].

\section{EXPERIMENTAL}

The Fe-Mn-Co, Fe-Mn-Si and Fe-Co alloys were prepared from pure elements by arc-melting several times under an Ar atmosphere. The resulting alloys, weighing 12 to $30 \mathrm{~g}$, were encapsulated in quartz under an $\mathrm{Ar}$ atmosphere, kept 48 hours at $1273 \mathrm{~K}$ for solution treatment and quenched in water at room temperature by breaking the capsules. Fe-Mn-Co and Fe-Mn-Si samples for dilatometric measurements were spark cut, 
encapsulated in quartz under Ar, annealed 1 hour at $1273 \mathrm{~K}$ and finally quenched in water. The martensitic transformation temperatures were determined by using a home-made dilatometer, with a Chromel-Alumel thermocouple welded on the sample. Fe-Co samples were spark cut from the alloys and machined into tubes with an internal diameter of $1 \mathrm{~mm}$ and an external one of $2 \mathrm{~mm}$. An Adamel-Lhomargy LK-02 dilatometer was used for heat treating the samples $15 \mathrm{~min}$ at $1273 \mathrm{~K}$ and then measuring the transformation temperatures. Small pieces from the samples were spark cut for analysing the chemical composition. The analysis was carried out by means of an electron microcobe using the wave dispersive energy (WDS) technique, and the pure metals as standards.

\section{RELATION BETWEEN DRIVING FORCES, $T_{0}$, THE $M_{S}$ AND A AATA}

A key step in the thermodynamic modelling of the martensitic transformation [6] is the evaluation of the Driving Force $\left(\Delta \mathrm{G}^{\mathrm{fcc} / \mathrm{hcp}}\right.$ ), which is defined as the Gibbs energy difference between the parent phase fcc $(\gamma)$ and the hcp $(\varepsilon)$ phase formed martensitically, i.e. the difference

$$
\Delta G_{m}^{\text {fce/hep }}=G_{m}^{\text {fcc }}-G_{m}^{\text {hcp }}
$$

for the fcc-to-hcp ("direct") transformation, and

$$
\Delta G_{m}^{h c p / f c c}=G_{m}^{h c p}-G_{m}^{f c c}
$$

for the hcp-to-fcc ("retransformation"). These quantities can be represented in an isobaric $\Delta \mathrm{G}_{\mathrm{m}}$ versus temperature plot, as in Fig.1.a. There we have indicated the so-called $\mathrm{T}_{0}$-temperature [6], at which we have

$$
\mathrm{G}_{\mathrm{m}}^{\mathrm{fcc}}\left(\mathrm{T}_{0}\right)=\left.\mathrm{G}_{\mathrm{m}}^{\mathrm{hcp}}\left(\mathrm{T}_{0}\right)\right|_{\mathrm{p}, \mathrm{x}=\mathrm{const}}
$$

It is assumed that the transformation can occur on cooling only when the Driving Force reaches a certain value, which will be referred to as the resistance to the (direct) transformation, $\Delta \mathrm{G}_{\mathrm{m}}^{*}\left(\mathrm{M}_{\mathrm{s}}\right)$. In the same way, we define the resistance to the retransformation $\Delta G_{m}^{*}\left(A_{s}\right)$, Fig.1.a. In principle, there is no simple, general relation between the $\mathrm{T}_{0}$-temperature calculated from the $G_{m}$ functions and the experimentally determined $M_{s}$ and $A_{s}$. Indeed [3], in the particular case in which (i) the $\Delta G_{m}$ versus $T$ function remains linear between $A_{S}$ and $M_{S}$ (Fig. 1.b.), and (ii) the resistances to the direct transformation and the retransformation are the same, the temperature differences $T_{0}$ $M_{s}$ and $A_{s}-T_{0}$ are equal, which yields

$$
\mathrm{T}_{0}=\frac{\left(\mathrm{M}_{\mathrm{S}}+\mathrm{A}_{\mathrm{S}}\right)}{2}
$$
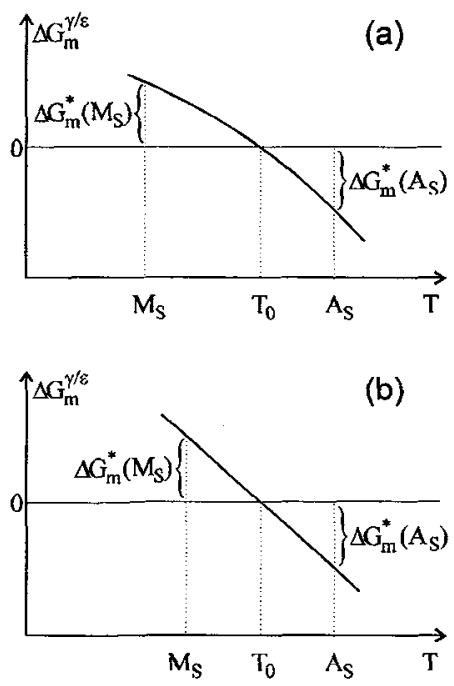

Figure 1. Schematic isobaric diagram showing: (a) the difference $G_{m}^{\gamma}-G_{m}^{\mathcal{E}}$ and the resistances to the $\gamma \rightarrow \varepsilon$ and $\varepsilon \rightarrow \gamma$ transformations, and (b) the particular case in which Eq. (4) holds exactly.

This equation is often used in the analysis of experimental data. However, it is evident that Eq.(4) cannot be exact if there is a significant heat-capacity difference between the fcc and the hcp phase. Such a difference is expected in the temperature range where the fcc phase orders antiferromagnetically, while hcp remains paramagnetic [3]. As a consequence, Eq. (4) will be used as an approximation, only in regions where the magnetic ordering effects are not important. 


\section{GIBBS ENERGY MODELLING OF THE Fe-Mn-Co SYSTEM}

The $G_{m}$ function of the fcc or hcp phase in the Fe-Mn-Co system was described by resolving it into a magnetic $\Delta \mathrm{G}^{\mathrm{mg}}$ and a non-magnetic contribution, acccording to the following expression

$$
\begin{aligned}
\mathrm{G}_{\mathrm{m}}^{\phi} & =\mathrm{x}_{\mathrm{Co}}{ }^{0} \mathrm{G}_{\mathrm{Co}}^{\phi}+\mathrm{x}_{\mathrm{Fe}}{ }^{0} \mathrm{G}_{\mathrm{Fe}}^{\phi}+\mathrm{x}_{\mathrm{Mn}}{ }^{0} \mathrm{G}_{\mathrm{Mn}}^{\phi}+\mathrm{RT}\left(\mathrm{x}_{\mathrm{Co}} \ln \mathrm{x}_{\mathrm{Co}}+\mathrm{x}_{\mathrm{Fe}} \ln \mathrm{x}_{\mathrm{Fe}}+\mathrm{x}_{\mathrm{Mn}} \ln \mathrm{x}_{\mathrm{Mn}}\right) \\
& +\mathrm{x}_{\mathrm{Co}} \mathrm{x}_{\mathrm{Fe}} \mathrm{L}_{\mathrm{Co}, \mathrm{Fe}}^{\phi}+\mathrm{x}_{\mathrm{Co}} \mathrm{x}_{\mathrm{Mn}} \mathrm{L}_{\mathrm{Co}, \mathrm{Mn}}^{\phi}+\mathrm{x}_{\mathrm{Fe}} \mathrm{x}_{\mathrm{Mn}} \mathrm{L}_{\mathrm{Fe}, \mathrm{Mn}}^{\phi}+\Delta \mathrm{G}_{\mathrm{m}}^{\mathrm{mg}, \phi}
\end{aligned}
$$

where $x_{i}(i=F e, M n, C o)$ is the atomic fraction of the element $i$ and ${ }^{0} G_{1}^{\phi}$ is the Gibbs energy of the element $i$ with the structure of the phase $\phi$ in a non-magnetic state. The necessary information about ${ }^{0} \mathrm{G}_{i}^{\phi}$ was taken from assessments of the thermodynamic properties of Fe [7], Co [8] and $\mathrm{Mn}$ [9]. The magnetic contribution $\Delta \mathrm{G}_{\mathrm{m}}^{\mathrm{mg}, \phi}$ was described by using the Hillert-Jarl [10] phenomenological model, which gives

$$
\Delta \mathrm{G}_{\mathrm{m}}^{\mathrm{mg}, \phi}=\mathrm{RT} \ln \left(\beta^{\phi}+1\right) \mathrm{f}^{\phi}\left(\tau^{\phi}\right)
$$

where $\beta^{\phi}$ is a composition dependent parameter related to the total magnetic entropy, i.e., the quantity $\Delta \mathrm{S}_{\mathrm{m}}^{\mathrm{mg}, \phi}(\infty)-\Delta \mathrm{S}_{\mathrm{m}}^{\mathrm{mg}, \phi}(0)$, as follows

$$
\Delta \mathrm{S}_{\mathrm{m}}^{\mathrm{mg}, \phi}(\infty)-\Delta \mathrm{S}_{\mathrm{m}}^{\mathrm{mg}, \phi}(0)=\mathrm{R} \ln \left(\beta^{\phi}+1\right)
$$

The variable $\tau^{\phi}$ is defined as $\mathrm{T} / \mathrm{T}_{\mathrm{N}}^{\phi}$ where $\mathrm{T}_{\mathrm{N}}^{\phi}$ is the Néel temperature of $\phi$ (fcc or hcp). When applying the model to alloys, $\beta^{\phi}$ and $T_{\mathrm{N}}^{\phi}$ are to be expressed as functions of composition. This was done as explained in refs.[11] and [12]. The composition dependent $\mathrm{L}_{\mathrm{ij}}^{\phi}(\mathrm{i}, \mathrm{j}=\mathrm{Co}, \mathrm{Fe}, \mathrm{Mn})$ parameters in Eq. (5) originate in the various binary subsystems of the present ternary, and account phenomenologically for the deviations from the ideal behaviour in the non-magnetic Gibbs energy. The $\mathbf{L}_{\mathrm{ij}}^{\phi}$ parameters for the fcc phase of the Fe-Co and $\mathrm{Mn}-\mathrm{Co}$ systems were directly taken from refs. [11] and [13], respectively. The fcc phase of the Fe-Mn system was treated using the $\mathrm{L}_{\mathrm{Fe}, \mathrm{Mn}}^{\mathrm{fcc}}$ value from ref. [14], but its $\beta^{\text {fcc }}$ vs. composition function was taken from our previous work $[3,4]$. The hcp phase in the Fe$\mathrm{Mn}$ and Mn-Co systems was described using

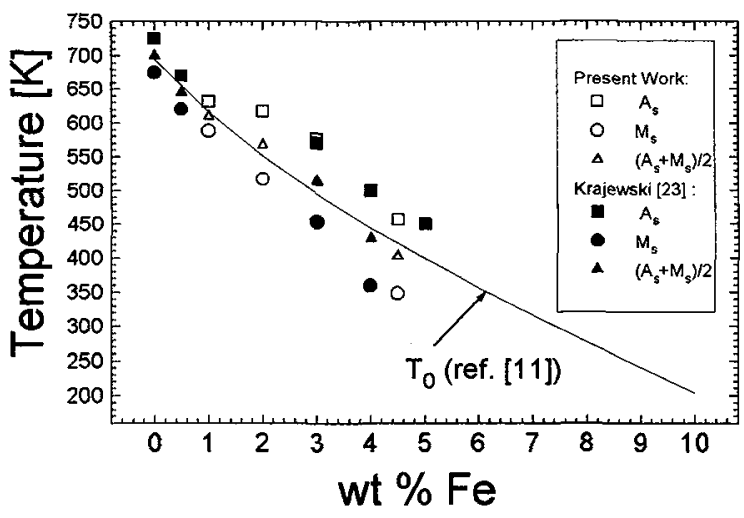

Figure 2. The $M_{S}$ and $A_{S}$ temperatures for Co-rich Fe-Co alloys according to the present work and ref. [23] (symbols). The $\mathrm{T}_{0}$-line calculated using the description presented in ref. [11] is also shown (solid line). the $\mathrm{L}_{\mathrm{ij}}^{\mathrm{hcp}}$ parameters reported in refs. $[3,4]$ and [13], respectively. The treatment of the hop phase is discussed in the next section.

5. To-TEMPERATURES IN Fe-Co AND Fe-Mn-Co ALLOYS: EXPERIMENTS AND THERMODYNAMIC CALCULATIONS

The thermodynamic properties of the Fe-Co system have previously been assessed by one of us (AFG) [11]. In particular the hcp phase was treated using the regular solution approximation (RSA), i.e. by 
assuming that $\mathrm{L}_{\mathrm{Co}, \mathrm{Fe}}^{\mathrm{hcp}}=\mathrm{x}_{\mathrm{Co}} \mathrm{x}_{\mathrm{Fe}}{ }^{0} \mathrm{~L}^{\text {hcp }}$, with an ${ }^{0} \mathrm{~L}^{\text {hcp }}$ parameter determined by searching for the best fit to experimental $T_{0}$ values from the literature, which concern Co-rich alloys. The $\mathrm{T}_{0}$ versus composition line recalculated using that thermodynamic description of $G_{m}^{f c c}$ and $G_{m}^{\text {hcp }}$ and solving Eq. (3) for $T_{0}$, is plotted in Fig. 2 (solid line) together with the present $M_{s}$ and $A_{s}$ measurements (symbols), and the $\mathrm{T}_{0^{-}}$ temperatures determined from these data by applying Eq.(4) (symbols). Figure 2 shows a good agreement between the calculation and the new experiments performed in the present work. However, calculations performed by us in the Fe$\mathrm{Mn}$-Co system using Eq. (5), and describing the Fe-Co hep phase with the ${ }^{0} \mathrm{~L}^{\text {hep }}$ parameter evaluated [11] from the Co-rich part of the FeCo system, gave $\mathrm{T}_{0}$-temperatures for $\mathrm{Fe}$-rich ternary alloys that are much lower than those measured in the present work. As a consequence, the description of the binary hcp phase was modified, and the subregular solution approximation (SSA), given by,

$\mathrm{L}_{\mathrm{Co}, \mathrm{Fe}}^{\mathrm{hcp}}=\mathrm{x}_{\mathrm{Fe}} \mathrm{x}_{\mathrm{Co}}\left[{ }^{0} \mathrm{~L}_{\mathrm{Co}, \mathrm{Fe}}^{\mathrm{hcp}}+{ }^{1} \mathrm{~L}_{\mathrm{Co}, \mathrm{Fe}}^{\mathrm{hcp}}\left(\mathrm{x}_{\mathrm{Co}}-\mathrm{x}_{\mathrm{Fe}}\right)\right]$

was adopted. The new, temperature independent ${ }^{0} \mathrm{~L}_{\mathrm{Co}, \mathrm{Fe}}^{\mathrm{hcp}}$ and ${ }^{1} \mathrm{~L}_{\mathrm{Co}, \mathrm{Fe}}^{\mathrm{hcp}}$ parameters were determined

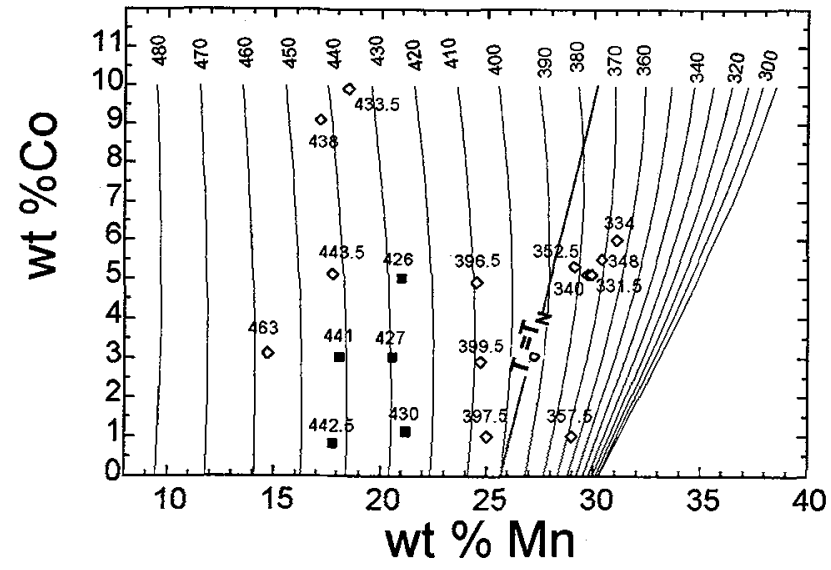

Figure 4. Calculated iso- $T_{0}$ lines for Fe-Mn-Co alloys (solid lines) compared with experimental data obtained in the present work. Solid symbols refer to values of $\left(\mathrm{M}_{S}+\mathrm{A}_{\mathrm{S}}\right) / 2$ used in the parameter evaluation procedure. Empty symbols refer to values of $\left(M_{S}+A_{S}\right) / 2$ which were not used.
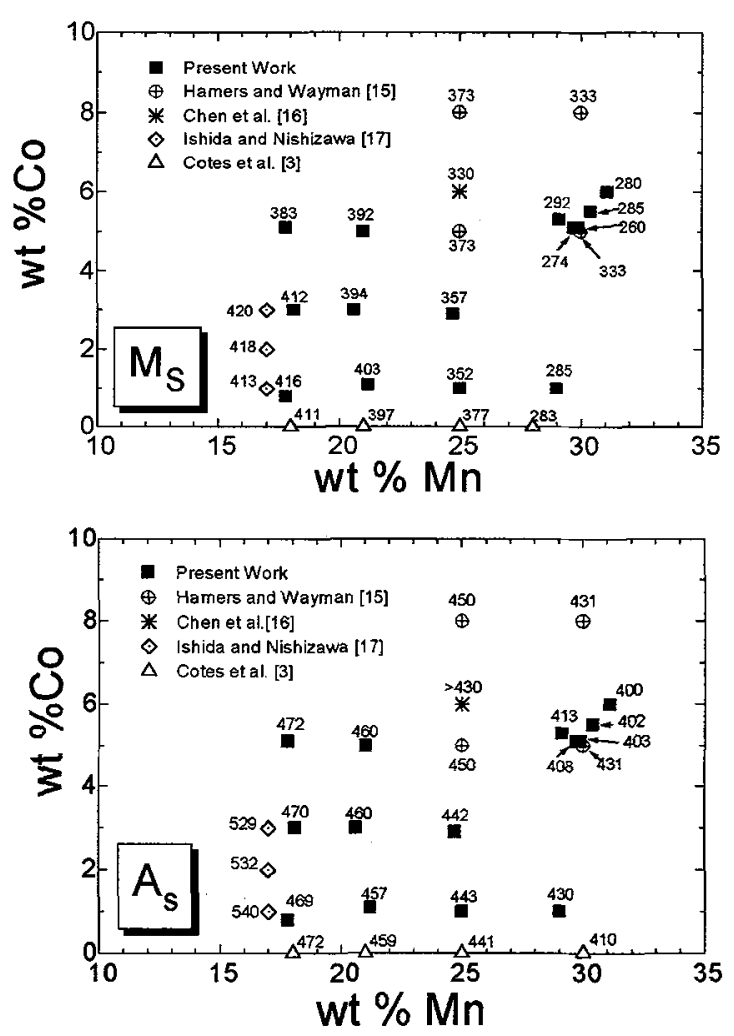

Figure 3. $M_{S}$ and $A_{S}$ temperatures for Fe-Mn-Co alloys measured in the present work compared with data from refs. [15-17]. The transformation temperatures for $\mathrm{Fe}-\mathrm{Mn}$ alloys are taken from ref. [3]

by searching for the best fit to an expanded database which included the literature data on $\mathrm{T}_{0}$ for Co-rich $\mathrm{Fe}-\mathrm{Co}$ alloys used in ref. [11], as well as a few, selected $T_{0}$ values, obtained from the $M_{s}$ and $A_{s}$ measured in the present study in Fe-Mn-Co alloys (Fig. 3). The recalculated iso- $T_{0}$ lines for ternary alloys are compared in Fig. 4 with the experimental information. As expected, the values obtained by applying Eq. (4) agree well with the $\mathrm{T}_{0}$-temperatures calculated thermodynamically by solving Eq. (3) only in the region where magnetic effects are not important, viz. in the region of low $\mathrm{Mn}$ content. In the region where $\mathrm{T}_{0}$

is almost equal to or lower than $\mathrm{T}_{\mathrm{N}}^{\gamma}$, the $\mathrm{M}_{\mathrm{S}}$ temperature is depressed by the magnetic ordering effect in fcc $[3,4]$ and thus Eq. (4) underestimates the $\mathrm{T}_{0^{-}}$ 
temperature of the alloy. A detailed account of these results will be given in a forthcoming paper.

6. $M_{S}$ AND $A_{S}$ TEMPERATURES IN THE Fe-Mn-Si SYSTEM: A DISCUSSION OF MEASURED AND CALCULATED VALUES

Recently, Forsberg and Ågren [5] analysed the MT temperatures in the Fe-Mn-Si system, using thermodynamic models, the parameters of which were fitted to experimental data, and presented a set of calculated iso- $\mathrm{M}_{\mathrm{S}}$ lines, Fig. 5. These lines suggest that at sufficiently high $\mathrm{Mn}$ contents the addition of $\mathrm{Si}$ to an alloy with a given wt \% Mn first increases and then decreases the $\mathrm{M}_{\mathrm{S}}$ temperature. Whereas the existence

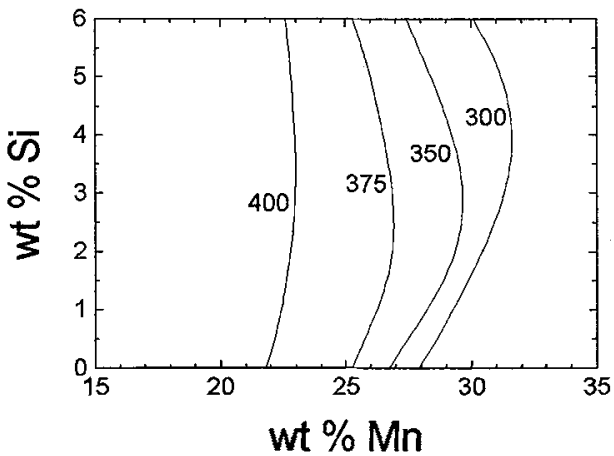

Figure 5. Iso-M $\mathrm{M}_{\mathrm{S}}$ lines for Fe-Mn-Si alloys according to a calculation by Forsberg and Ågren [5]. of such behaviour is, in principle, not impossible, it is unexpected in the Fe-Mn-Si system, which has motivated a search by us for additional experimental information on the role of $\mathrm{Si}$ additions to $\mathrm{Fe}-\mathrm{Mn}$ alloys. As a first step of our systematic study we critically analysed the $\mathrm{M}_{S}$ and $\mathrm{A}_{\mathrm{S}}$ data used by Forsberg and Ågren [5] to determine the phenomenological parameters of their $G_{m}$ functions. Those data will now be reviewed, and compared with the information previously obtained by us $[3,4]$ in the Fe-Mn system, and the present measurements in some Fe-Mn-Si alloys. In Fig. 6 we show the iso-M lines one would obtain by combining the binary data by Cotes et al. [3] with those of Murakami et al. [18], Donner et al. [19], Andersson et al.[20], and Maki et al. [21]. Alternatively we present in Fig. 7 a set of iso-

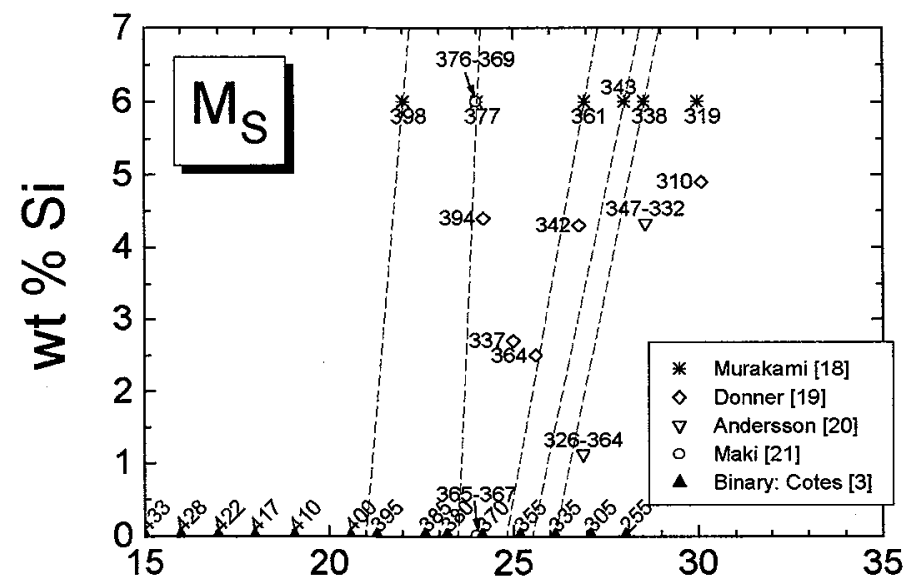

Figure 6. A set of possible iso- $\mathrm{M}_{\mathrm{s}}$ lines (dashed lines) drawn by using data from refs. [18-21] on Fe-Mn-Si alloys (symbols) and from ref. [3] on Fe-Mn alloys.
$\mathrm{M}_{\mathrm{S}}$ lines based on our binary data [3], the ternary results by Sade et al.[22], and the present values for Fe-Mn-Si alloys. In spite of the experimental scatter, the assumption that the iso$\mathrm{M}_{\mathrm{S}}$ lines are straight lines makes it possible to account for a large number of data points. In particular, the combination of the ternary results [18-21] with binary data [3] in Fig. 6 leads to almost vertical iso- $\mathrm{M}_{\mathrm{S}}$ lines, a feature which is observed in the iso$\mathrm{M}_{\mathrm{S}}$ lines calculated by Forsberg and Ågren [5] in the low Mn range (Fig. 5). However, the combination of our binary [3] and ternary results with another set of experimental data from the literature [22] in Fig. 7 leads to iso- $\mathrm{M}_{\mathrm{S}}$ with a different slope. It is noteworthy that this slope agrees well with the initial slope of Forsberg

and Ågren's [5] calculated lines at large Mn contents, Fig. 5. It is evident that the available experimental information is not accurate enough for a detailed discussion of the effect of Si additions to the Fe-Mn system. The present analysis of the data reveals systematic discrepancies between the various authors, which makes it difficult to establish unambiguously the iso- $\mathrm{M}_{\mathrm{S}}$ and iso- $\mathrm{A}_{\mathrm{S}}$ lines in a wt \% Mn vs. wt \% Si plot. Therefore, it is not possible to decide whether the shape of the iso- $\mathrm{M}_{\mathrm{S}}$ lines calculated in ref. [5] does reflect a true physical effect of the $\mathrm{Si}$ additions, or if that shape is simply a consequence of the fitting procedure 
[5] using experimental information from the seemingly inconsistent datasets (Figs. 6 and 7) as input. Additional experimental data in the high Si range would help to answer this question. An experimental investigation of that composition range is under way in our laboratory.

\section{ACKNOWLEDGMENTS}

S. Dutrús performed the microprobe analysis. F. Fürst and C. Klenner encapsulated alloys and samples. $P$. Bavdaz helped us with the dilatometric measurements.

\section{REFERENCES}

[1] Enami K., Nagasawa A. and Nenno S., Scripta Metallurgica, 9 (1975) pp 941-48.

[2] Kaufman L. and Bernstein $H_{\text {, }}$ "Computer Calculation of Phase Diagrams", Academic Press, New York, 1970.

[3] Cotes S. M., Baruj A., Sade M. and Fernández Guillermet A., Journal de Physique IV, Colloque C2, 5 (1995), pp 83-88.

[4] Cotes S. M., Sade M. and Fernández Guillermet A., Metallurgical Transactions A, (in press).

[5] Forberg A. and Ågren J., Journal of Phase Equilibria, 14 (1993) 3, pp 354-363.

[6] Kaufman L.and Hillert M., Martensite, edited by G.B. Olson and W.S. Owen. ASM International, USA, 1992, pp. 41-58.

[7] Fernández Guillermet A., Gustafson P. High Temp.-High-Press., 6 (1985) pp 591-610.

[8] Fernández Guillermet A., Internat. Journ. Thermophysics, 8 (1987) pp 481-510.

[9] Fernández Guillermet A and Huang W., Internat. Journ. Thermophysics, 11 (1990) pp 949-69.

[10] Hillert M. and Jarl M., Calphad, 2 (1978) pp 227-238.

[11] Fernández Guillermet A., High Temp.- High Press., 19 (1987) pp 477-499.

[12] Huang W., CALPHAD, 14 (1990) 1, pp 11-22.

[13] Huang W., CALPHAD, 13 (1989) pp 231-242.

[14] Huang W., CALPHAD, 13 (1989) pp 243-252.

[15] Hamers A. A. H. and Wayman C. M., Scripta Met. and. Mater., 25 (1991), pp 2723-2728.

[16] Chen C. F., Yang J. H. and Zhao L., MRS., 9 (1988) pp 481-48

[17] Ishida K. and Nishizawa T., Trans. JIM, 15 (1974), pp 225-31.

[18] Murakami M., Tsuda H., Suzuki H.G. and Matsuda S., "Complete Shape Memory Effect in Polycrystalline Fe-Mn-Si Alloys", Proceedings of the International Conference on Martensitic Transformations, Nara 26-30 August 1986, The Japan Institute of Metals (1987), pp 985-990.

[19] Donner P., Hornbogen E. and Sade M., J. of Mat. Sci Letters, 8 (1989) pp 37-40.

[20] Andersson M., Forsberg A. and Agren J., TRITA-MAC-0532 (1993), The Royal Institute of Technology, Sweden.

[21] Maki T. and Tsuzaki K., "Transformation behavior of $\varepsilon$-Martensite in Fe-Mn-Si Shape Memory Alloys", Proceedings of the International Conference on Martensitic Transformations", Monterey 20-24 July 1992, C. M. Wayman and J. Perkins Eds. (Monterey Institute of Advanced Studies, Carmel, USA, 1993) pp 1151-1162.

[22] Sade M., K. Halter K., Hornbogen E., Z. Metallkde. Bd 79 (1988) H.8, pp 487-491.

[23] Krajewski W., Krüger J. and Winterhager H., Metall. J. 24 (1970) 480-487. 